\title{
SUSTENTABILIDADE DA PRODUÇÃO DE CANA-DE-AÇÚCAR EM USINAS NO ESTADO DE SÃO PAULO
}

\author{
Fernando Rodrigues de Amorim* \\ Marco Tulio Ospina Patino** \\ Gilson Rogério Marcomini***
}

RESUMO: O Brasil é um país que se destaca na produção de cana-de-açúcar por apresentar efetivos rendimentos agrícolas e eficiência industrial, se comparada a outras culturas que também servem para a produção de etanol, como o milho e a beterraba. Entretanto o setor tem apresentado quedas na produção e, consequentemente, no desempenho financeiro das empresas. Este trabalho comparou a estratégia de gestão agrícola de usinas exportadoras e não exportadoras do Estado de São Paulo. Caracteriza-se como uma pesquisa exploratória, com coleta de dados estruturada na técnica de multicasos, ênfase na análise quantitativa e análise da correlação de variáveis integrantes dos aspectos econômico, social e ambiental. O resultado relacionado ao aspecto econômico mostrou que há um melhor desempenho financeiro nas empresas que exportam seus produtos. Em relação ao âmbito social, não se diferem os benefícios das empresas exportadoras de seus subprodutos das que não exportam e também não se difere a quantidade de tonelada de cana-de-açúcar que um trabalhador executa. Em relação ao aspecto ambiental, a impermeabilização dos canais de vinhaça no período da safra das empresas exportadoras não é executada, assim como a incorporação do fertilizante nitrogênio. No entanto, as usinas exportadoras relatam menores problemas com erosão do solo.

PALAVRAS-CHAVE: Ambiental; Econômico; Social.

\section{SUSTAINABILITY OF SUGARCANE PRODUCTION IN PLANTS IN THE STATE OF SÃO PAULO, BRAZIL}

ABSTRACT: Sugarcane production in Brazil is highlighted due to high agricultural profits and industrial efficiency when compared to other crops, such as corn and

Doutorando em Engenharia Agrícola pela Universidade Estadual de Campinas (UNICAMP). Brasil.

E-mail: fernando-r-a@hotmail.com

** Doutor em Agronomia; Atualmente é professor na Faculdade de Engenharia Agrícola (FEAGRI - UNICAMP). Brasil

*** Doutorando em Engenharia Agrícola pela Universidade Estadual de Campinas (UNICAMP). Brasil. 
beetroot, also used in the production of ethanol. Decrease in production and, consequently, financial performance, has been registered. Current paper, an exploratory research with data collection structured on multi-case technique, emphasis on quantitative analysis and analysis of the co-relationship of variables which integrate economic, social and environmental aspects, compared the agricultural strategy of exporting and non-exporting plants in the state of São Paulo, Brazil. Economy-related results showed that a better financial performance exists in export firms. The social aspects reveal that the benefits of firms exporting their byproducts are not different from those that do not export. The quantity of a ton of sugarcane executed by a worker is not different. In the case of the environment, firms fail to execute the impermeability of stillage channels during harvest time and the incorporation of the fertilizer nitrogen. However, export firms report less problems in soil erosion.

KEY WORDS: Environmental; Economic and social features.

\section{INTRODUÇÃO}

A produção e o processamento da cana-de-açúcar é um importante setor do agronegócio brasileiro e a produção de açúcar e etanol, tanto para consumo interno como para exportação, contribui diretamente para o resultado da balança comercial e em geral para o desenvolvimento do país.

Nesse sentido, o valor bruto da produção (VBP) da cana-de-açúcar do Estado de São Paulo em 2016 correspondeu a R\$ 52,8 bilhões, que é equivalente a 17\% de toda produção vegetal, sendo inferior somente da soja 116,2 bilhões (BRASIL, 2017). Este valor é representativo por ocupar $67 \%$ de todas as culturas cultivadas deste Estado (SILVA et al., 2015).

Entretanto o setor passa por dificuldades econômicas, pois, somente em 2015, foram 13 usinas no Brasil que entraram com pedido de concordata e falência no Brasil (NOVA CANA, 2016a). No entanto, Trevisoli e Neves, (2015) e Nova Cana (2016b) relataram que ocorreu um alto nível de endividamento do setor em 2015, que ultrapassou os 95 bilhões de reais. Todavia segundo Conab (2017), este valor representa um valor maior que a receita obtida no setor, nesse ano, de 50,2 bilhões de reais, queda de 22\% em relação à safra 2014-2015.

Além dessas dificuldades, outro problema é a queda na produtividade dos 
canaviais decorrente do clima e a falta de investimento na sua renovação (TREVISOLI; NEVES, 2015). A produção da safra 2014-2015 foi de 571,344 milhões, queda de $4,31 \%$ em relação à safra anterior, com uma média de produção de 74 toneladas por hectare, queda de aproximadamente 5\% em relação à safra passada (UNICA, 2016a).

A parte ambiental do setor é um dilema, pois vários trabalhos indicam que as agroindústrias do setor sucroalcooleiro apresentam inúmeros riscos em relação aos impactos ambientais. Esses impactos são ocasionados na fase agrícola e na fase industrial (LANGOWSKI, 2007; OLIVEIRA, 2009; PIACENTE, 2005).

Dentre vários aspectos do setor agrícola esta pesquisa abrange aspectos ambientais como a contaminação das águas superficiais e do solo através da aplicação excessiva de adubos, corretivos minerais e a erosão do solo em áreas de renovação da lavoura.

Buscando alternativas para diminuir o impacto negativo desses problemas e se manter de forma competitiva na atividade, algumas usinas do Brasil estão conseguindo uma remuneração melhor com a exportação de etanol para a Califórnia e assim o volume exportado de etanol entre janeiro a setembro de 2015, para esse destino, chegou a 575 milhões de litros de etanol (BIOMASSABIOENERGIA, 2015).

Entretanto, para entrar e permanecer nesse mercado, as usinas precisam obter o registro junto a Agência de Proteção Ambiental (Environmental Protection Agency - EPA $)^{4}$. Assim, a obtenção e utilização desse registro, concedido pelo Conselho de Qualidade do Ar da Califórnia (California Air Resources Board), que é a entidade responsável em avaliar se a usina está apta a exportar etanol de acordo com o Padrão de Combustível de Baixo Carbono (Low Carbon Fuel Standard) (UNICA, 2015a), se converte em uma estratégia de gestão para manter a competitividade no mercado.

No aspecto social, alguns estudos (ALVES, 2006; BACCARIN, 2008) mostraram que a execução do corte da cana-de-açúcar de forma manual pode acarretar acidentes de trabalho e até mortes, pelas condições adversas do trabalho e adoção de posturas incorretas, realização de movimentos corporais bruscos e repetitivos e intenso esforço físico. Contudo, com a mecanização da colheita e do plantio, outras variáveis como a qualificação dos trabalhadores e o desemprego gerado pelas ativi-

4 Ambiental (Environmental Protection Agency - EPA) esta agência é responsável pelas normas que regulamentam a produção e a utilização de biocombustíveis no Estado americano da Califórnia. 
dades mecanizadas merecem estudos específicos.

Com base nestas premissas e afirmações, o desafio do setor sucroalcooleiro é satisfazer as necessidades do presente, sem comprometer a capacidade produtiva das futuras gerações e, consequentemente a satisfação de suas necessidades. Portanto, a administração dos fatores de produção baseados no princípio da sustentabilidade deve levar em consideração a integração dos componentes econômico, social e ambiental como estratégia para alcançar a sustentabilidade.

Bhinge et al. (2015) utilizam o termo sustentabilidade nos parâmetros social, ambiental e econômico, dentro de seu estudo sobre a otimização de sustentabilidade para a tomada de decisão da cadeia de fornecimento global. Assim, este trabalho foi desenvolvido com o intuito de responder a questões relacionadas aos componentes econômico, social e ambiental da sustentabilidade.

As premissas relacionadas ao componente econômico indicam que as usinas exportadoras que utilizam na parte agrícola um maior percentual da torta de filtro e da vinhaça têm um custo operacional menor e que as usinas que exportam conseguem um preço maior do que o praticado no mercado interno.

No componente social afirma-se que na colheita mecanizada as usinas exportadoras alcançam uma média diária de cana cortada por trabalhador menor do que as usinas que não exportam e as usinas exportadoras concedem maiores reajustes, prêmios e benefícios por produtividade aos funcionários em comparação às usinas que não exportam.

Com relação ao componente ambiental alega-se que no período de safra as usinas exportadoras mantêm a impermeabilização dos canais de condução da vinhaça, que essas empresas apresentem menor erosão e que a aplicação de nitrogênio nos tratos culturais é incorporado ao solo nessas empresas.

Portanto o objetivo desta pesquisa foi comparar a estratégia de gestão agrícola de usinas exportadoras e não exportadoras localizadas no Estado de São Paulo, analisando a correlação de variáveis pertencentes aos componentes econômico, social e ambiental da sustentabilidade. 


\section{METODOLOGIA}

Com base no objetivo geral, a presente pesquisa foi realizada em caráter exploratório, que procura desenvolver, esclarecer e modificar novos conceitos no intuito de formular teorias mais precisas e/ou hipóteses. Caracteriza-se pelo estudo profundo de um, ou de poucos objetos, de maneira que permita seu amplo e detalhado conhecimento acerca de um determinado assunto (GIL, 2009).

Com relação ao delineamento, o presente trabalho é classificado como uma pesquisa de associação com interferência. Esse tipo de pesquisa testa a correlação entre os tratamentos, pois a interferência de uma ou mais variáveis interferem nas outras. Verificada a interferência tem-se o mecanismo definido como a sequência de eventos (de interferência) que liga o agente. Entretanto a relação não é absoluta, "pois os fenômenos podem ser complexos e um conjunto de variáveis pode interagir concomitantemente de forma que a movimentação de apenas uma delas seja insuficiente para provocar efeito perceptível" (VOLPATO, 2015, p. 7).

As informações para este projeto foram coletadas durante os meses de julho e agosto de 2016 através de questionários respondidos por gerentes e supervisores de cinco usinas localizadas no Estado de São Paulo, diretamente envolvidos com funções e/ou atividades relacionadas ao setor agrícola. As questões eram relacionadas com as variáveis que influenciam os aspectos ambientais, econômicos e sociais dessas empresas, sendo que as três usinas exportadoras de açúcar e etanol tinham a autorização emitida pela Agência de Proteção Ambiental (Environmental Protection Agency - EPA) e foram identificadas como usinas 1, 3 e 5 . As empresas não exportadoras foram identificadas como as usinas 2 e 4 .

O questionário composto de 37 questões foi enviado via e-mail e após tabulação das respostas em planilhas Excel, foi utilizado o programa R e os softwares Vegan e Stats. A análise e interpretação dos dados foram efetuadas usando um nível de significância de 5\% e métodos que analisam a dependência entre variáveis e permitem analisar situações quando uma ou mais variáveis são explicadas por outras variáveis conhecidas como independentes.

Também foi utilizada a correlação linear de Sperman (S), uma técnica de interdependência usada quando nenhuma variável ou grupo de variáveis são tratadas como dependentes ou independentes (FERRAUDO, 2014). A correlação de 
Sperman usa uma estimativa de correlação baseada em ranking, ou seja, as variáveis são categorizadas em ordem consecutiva de acordo com os valores observados. $\mathrm{O}$ resultado da correlação pode ser interpretado como a proporção da variabilidade de uma variável que é correspondente à outra e o valor de correlação varia entre 1 e -1, sendo que valores negativos representam uma correlação inversa, quando uma variável aumenta em valor, a outra diminui.

Também foi utilizada a distância de Jaccard, calculada para cada par de usinas de forma a comparar quais usinas são mais próximas em termos dos produtos principais que produzem

A distância Jaccard mede a dissimilaridade entre os conjuntos de amostras, e é obtida subtraindo o coeficiente Jaccard de 1, ou, de forma equivalente, dividindo a diferença dos tamanhos da união e a interseção de dois conjuntos pelo tamanho da união:

$$
\text { Distância de Jaccard } \text { Ja,b }_{a}=\frac{|A \mathbf{u} B|-|A \cap B|}{|A \mathbf{u} B|}
$$

\section{RESULTADOS E DISCUSSÕES}

Dentre os principais produtos exportados pelas usinas, o etanol hidratado e o etanol anidro são os mais representativos no faturamento das empresas nos últimos dois anos (Tabela 1), seguidos do açúcar Very High Polarization (VHP), açúcar cristal, açúcar refinado e levedura seca.

Tabela 1. Porcentagem das usinas e a relação com faturamento através da exportação de seus produtos em 2014 e 2015

\begin{tabular}{c|c}
\hline Produto & Usinas (\%) \\
\hline Etanol hidratado & $100 \%$ \\
\hline Etanol anidro & $100 \%$ \\
\hline Açúcar VHP & $60 \%$ \\
\hline Açúcar cristal & $40 \%$ \\
\hline Açúcar refinado & $40 \%$ \\
\hline Levedura seca & $20 \%$ \\
\hline
\end{tabular}

Fonte: Elaborado pelos autores a partir de pesquisa de campo (2016). 
A Tabela 2 mostra a Distância de Jaccard entre pares de usinas, calculado a partir de dados sobre os principais produtos em termos de faturamento nos últimos dois anos. As usinas 1 e 3, e 2 e 4, são similares com relação aos seus produtos principais em termos de faturamento.

Tabela 2. Distância de Jaccard entre pares de usinas, calculado a partir de dados sobre o principal produto em termos de faturamento em 2014 e 2015

\begin{tabular}{c|c|c|c|c|c}
\hline & Usina 1 & Usina 2 & Usina 3 & Usina 4 & Usina 5 \\
\hline Usina 1 & 0.00 & & & & \\
\hline Usina 2 & 0.67 & 0.00 & & & \\
\hline Usina 3 & 0.00 & 0.67 & 0.00 & & \\
\hline Usina 4 & 0.67 & 0.00 & 0.67 & 0.00 & \\
\hline Usina 5 & 0.57 & 0.40 & 0.57 & 0.40 & 0.00 \\
\hline
\end{tabular}

Fonte: Elaborado pelos autores a partir de pesquisa de campo (2016).

Os resultados da distância de Jaccard indicam que os mesmos produtos foram responsáveis pela maior parte do faturamento entre as usinas 1 e 3 e entre as usinas 2 e 4 . Das cinco usinas analisadas três exportam seus produtos, porém nenhuma exporta para a América do Sul, uma exporta para os EUA, e todas exportam para a Ásia (Tabela 3).

A correlação de Sperman $(s=0,89)$, índice considerado de alta correlação, verificou que as usinas com maior porcentagem da produção destinada ao mercado externo têm maior adição no preço devido à exportação. Esse resultado também indicou que as empresas que exportam para a África e Oceania têm um maior incremento no preço quando comparado com o preço no mercado nacional. 
Tabela 3. Adição no lucro para as usinas que exportam para determinadas regiões do mundo em comparação com o mercado interno

\begin{tabular}{c|c|c|c|c|c}
\hline Usina & EUA & ÁSIA & ÁFRICA/OCEANIA & $\begin{array}{c}\text { ADIÇÃO AO } \\
\text { PREÇO }\end{array}$ & $\begin{array}{c}\text { \% PRODUÇÃO } \\
\text { Mercado externo }\end{array}$ \\
\hline 1 & 0 & 1 & 0 & $10 \%$ & $30 \%$ \\
\hline 2 & 1 & 0 & 0 & $0 \%$ & $0 \%$ \\
\hline 3 & 0 & 1 & 1 & $10 \%$ & $50 \%$ \\
\hline 4 & 0 & 0 & 0 & $0 \%$ & $0 \%$ \\
\hline 5 & 0 & 1 & 1 & $20 \%$ & $100 \%$ \\
\hline
\end{tabular}

Fonte: Elaborado pelos autores a partir de pesquisa de campo (2016).

A Tabela 3 indica as relações entre o local para onde os produtos são exportados e a adição ao preço no mercado externo comparado com o interno. Os resultados corroboraram a literatura ao confirmar que as usinas estão conseguindo uma remuneração melhor com a exportação de etanol, algo em torno de $22 \%$ de aumento, quando comparado aos preços no mercado interno do Brasil (BIOMASSABIOENERGIA, 2015).

Existe uma correlação forte indicada por um valor da correlação de Sperman de 0,77 entre a as empresas que não impermeabilizam os canais de vinhaça durante a safra e o destino dos produtos da empresa. Isso se deve a que apenas uma empresa segue a legislação vigente a este respeito. Entretanto, as empresas que exportam e receberam algum tipo de notificação ambiental apresentam uma correlação moderada (s $=0,61)$.

Como indicado por De Souza et al. (2015), a concentração de vinhaça no solo e no lençol freático aumenta a presença de diversos metais pesados como amônia, magnésio, alumínio, ferro, cloreto de potássio e a matéria orgânica.

A recomendação do órgão responsável no Estado de São Paulo, a Companhia Ambiental do Estado de São Paulo - CETESB (2006, p. 6-12), admite a utilização da vinhaça desde que haja vedação específica nessa prática e os tanques de armazenamento de vinhaça deverão atender ao disposto desta norma e ser impermeabilizados com geomembrana impermeabilizante ou outra técnica de igual ou superior efeito.

Três das cinco usinas tiveram problemas com erosão e precisaram refazer o plantio de cana-de-açúcar com a perda evidente de matéria orgânica que o replantio 
acarreta. Quando o processo de erosão é muito intenso, aumenta o estado de degradação das áreas ocupadas com a cana-de-açúcar (WEILL; SPAROVEK, 2008).

Em três das empresas, o nitrogênio, na forma de nitrato de amônia, é aplicado no solo com implementos que lançam o adubo superficialmente, sem a incorporação do fertilizante na terra. Nesse sentido Brandão (2014, p. 339) explica que "o nitrogênio aplicado no solo pode ser perdido por diversas formas como por volatilização, lixiviação, desnitrificação e imobilização. Assim, nem todo nitrogênio aplicado torna-se disponível para a planta”.

O custo operacional do plantio $(s=0,16)$, correlação muito fraca, não difere entre as empresas, independente da quantidade exportada, assim como o custo operacional do corte, carregamento e transporte $(s=0,23)$, correlação baixa. Todavia o maior percentual do custo de produção de açúcar e etanol corresponde à parte agrícola, com $60 \%$ do custo total da produção (SILVA, 2009).

Para quatro das empresas, o custo operacional para o plantio do canavial (preparo de solo, mão de obra, insumos, mecanização e outros) na safra 2014 e 2015 ficou acima de $\mathbf{R} \$ 5.000,00$ por hectare. Nas cinco usinas analisadas o custo do manejo da cana seca fica entre $\mathrm{R} \$ 1.000$ e $\mathrm{R} \$ 2.000$, mas, este valor poderia ser mais elevado, pois três das empresas utilizam seus subprodutos (torta de filtro, cinza e vinhaça) como fertilizantes em 30-50\% de suas áreas. 40\% das empresas utilizam seus subprodutos em $70 \%$ de suas áreas. O maior uso de torta de filtro e vinhaça tem uma correlação s $=0,61$, correlação moderada para 2014 e 2015 com a produtividade.

As cinco usinas efetuam plantio e colheita mecanizada e em $60 \%$ da colheita o desempenho operacional das máquinas está acima de 600 toneladas por dia de trabalho. Existe correlação muito forte $(s=0,96)$ entre a média diária de cana cortada por trabalhador e a quantidade exportada e as usinas que exportam apresentam menor quantidade diária de cana cortada por trabalhador. As respostas indicam que $40 \%$ dos trabalhadores cortam entre 10 e 12 toneladas por dia, $20 \%$ entre 6 e 8 toneladas, $20 \%$ entre 8-10 toneladas e $20 \%$ até 6 toneladas. Esse resultado confirma que independente do destino dos subprodutos das empresas, os trabalhadores têm uma média elevada de produção diária.

Este fato confirma os valores apresentados por Alves (2006) e Segato e Pereira (2006), indicando que um trabalhador braçal colhia na década de 80 em média de 6 a 8 toneladas de cana queimada passando na primeira década do século XXI para 12 toneladas de cana queimada/dia e de 3 a 4 toneladas de cana crua/dia. 
A correlação entre as empresas com preço superior de seus produtos e as que oferecem cesta básica a seus funcionários $(s=0,16)$, correlação muito fraca. No entanto, existe uma correlação negativa $(s=-0,3)$ correlação fraca, das empresas com esse preço e a escolaridade dos funcionários indica a necessidade de programas de educação, treinamento e capacitação nessas empresas.

A correlação entre a porcentagem da produção destinada à exportação e benefícios como reajuste salarial acima da inflação $(s=0,64)$ correlação moderada, plano odontológico $(s=0,63)$ correlação moderada, convênio com farmácia ( $\mathrm{s}=$ $0,81)$, correlação forte, vale transporte $(s=0,77)$ correlação forte e vale alimentação ( $s=0,45)$ correlação moderada, mostra a estratégia de incentivos das empresas exportadoras.

\section{CONSIDERAÇÕES FINAIS}

As premissas relacionadas ao componente econômico das usinas exportadoras entre as variáveis dependentes e independentes foram todas comprovadas.

No aspecto social, independente da exportação de seus produtos, as usinas apresentam reajustes e benefícios que se convertem em incentivos para os trabalhadores dessas empresas.

A afirmação referente à impermeabilização dos canais de vinhaça no período da safra correlacionada ao destino dos produtos não foi comprovado, assim como a incorporação do fertilizante nitrogênio. Quanto ao destino dos produtos e notificação ambiental as cinco usinas apresentaram correlação positiva. No entanto, a usina que é exportadora apresenta poucos problemas de erosão.

\section{REFERÊNCIAS}

ALVES, F. Por que morrem os cortadores de cana? Saúde e Sociedade, v. 15, n. 3, p. 90-98, 2006. Disponível em: <http://www.revistas.usp.br/sausoc/article/ view/7496/9009>. Acesso em: 31 mar. 2016.

BACCARIN, J. G.; ALVES, F. J. C.; GOMES, L. F. C. Emprego e condições de trabalho 
dos canavieiros no Centro-Sul do Brasil, entre 1995 e 2007. In: CONGRESSO DA SOCIEDADE BRASILEIRA DE ECONOMIA, 46., 2008, Rio Branco. Anais... Rio Branco: SOBER, 2008. p. 1-21. Disponível em: < http://www.sober.org.br/palestra/9/569. pdf > . Acesso em: 26 mar. 2016.

BRANDÃO, N. Z.; SOFIATTI, V.; SANA, S. R.; RESENDE, V. A.; MEDEIROS, C. J. Suplementação nitrogenada para o algodoeiro usando dados hiperespectrais obtidos por espectrorradiometria e imagens do sensor AWiFs do ResourseSat -1. p. 338-346. In: BERNARDI, C. C. A.; NAIME, M. J.; RESENDE, V. A.; BASSOI, H. L.; INAMASU, Y. R. Agricultura de Precisão: Resultados de um novo olhar. Brasília. Embrapa. 2014. Disponível em: <https://www.macroprograma1.cnptia.embrapa.br/redeap2>. Acesso em: 26 ago. 2015.

BRASIL. Valor da produção de 2016 fecha em R \$ 527,9 bilhões. 2017. Disponível em: < http://www.agricultura.gov.br/noticias/valor-da-producao-de-2016-fecha-em-r-527-9-bilhoes/vpb-principais-produtos.pdf> . Acesso em: 12 out. 2017.

BIOMASSABIONERGIA. Sustentabilidade é a chave. n. 1. Ed. 11. 2015. Disponível em: < https://www.biomassabioenergia.com.br/edicao> . Acesso em: 15 maio 2016.

BHINGE, R.; MOSER, R.; MOSER, E.; LANZA, G.; DORNFELD, D. Sustainability optimatization for global supply chain decision-making. Procedia CIRP, v. 26, p. 323-328, 2015. Disponível em: < http://www.sciencedirect.com/science/article/pii/ S2212827114009184>. Acesso em: 11 jun. 2016.

COMPANHIA AMBIENTAL DO ESTADO DE SÃO PAULO. (CETESB) 2006. Normas técnicas. Vinhaça - critérios e procedimentos para aplicação no solo agrícola. Disponível em: <http://www.cetesb.sp.gov.br/wp-content/uploads/sites/11/2014/12/ DD-045-2015-C.pdf>. Acesso em: 16 maio 2016.

COMPANHIA NACIONAL DE ABASTECIMENTO. CONAB. 2017. Indicadores da Agropecuária, ano XXVI, n. 09, set. 2017. Disponível em: < http://www.conab.gov. br/conteudos.php?a $=1522 \& \mathrm{t}=>$. Acesso em: 13 out. 2017.

FERRAUDO, A. S. Técnicas de Análise Multivariada: uma introdução. Apostila técnica. Curso Análise Exploratória de Dados - Estatística Multivariada, Universidade Estadual Paulista - UNESP, 2014. 
GIL, A. C. Como elaborar projetos de pesquisa. 4. ed. São Paulo: Atlas, 2009.

NOVACANA. As usinas de açúcar e etanol do Brasil. 2016a. Disponível em: <https://www.novacana.com/usinas-brasil/> . Acesso em: 26 abr. 2016.

NOVACANA. O destino está praticamente selado para as 85 usinas em recuperação judicial no Brasil. 2016b. Disponível em: < https://www.novacana.com/n/ industria/usinas/destino-selado-85-usinas-recuperacao-judicial-brasil-280116/ $>$. Acesso em: 09 maio 2016.

PIACENTE, F. J. Agroindústria canavieira e o sistema de gestão ambiental: o caso das usinas localizadas nas bacias hidrográficas dos rios Piracicaba, Capivari e Jundiaí. Dissertação (Mestrado em economia) - Universidade Estadual de Campinas (UNICAMP), 2005. Disponível em: < http://repositorio.unicamp.br/jspui/ handle/REPOSIP/286129> . Acesso em: 16 maio 2016.

SPAROVEK, G.; BARRETTO, A. K. I.; PAPP, L.; LINO, J. A revisão do código florestal brasileiro. Novos Estudos, v. 89, p. 111-135, 2011. Disponível em: < http://www. scielo.br/scielo.php?script $=$ sci_arttext\&pid $=$ S0101-33002011000100007 $>$. Acesso em: 14 maio 2016.

SILVA, A. F.; BARROS, G. S. C.; FACHINELLO, A. L.; CASTRO, N. R. Perfil do agronegócio paulista e sua participação em âmbito nacional. 2015. p. 97-113. Disponível: < <ttp://www.agricultura.gov.br/arq_editor/RPA\%204\%202015.pdf> . Acesso em: 20 maio 2016.

SOUZA, J. K. C.; MESQUITA, F. O.; SOUZA, M. M. A.; FARIAS, C. H. A.; MENDES, H. C.; NUNES, M. A. Fertirrigação com vinhaça na produção de cana-de-açúcar. ACSA. v. 11, n. 2, p. 7-12, 2015. Disponível em: < http://revistas.ufcg.edu.br/acsa/index.php/ ACSA/article/view/532 > . Acesso em: 16 maio 2016.

TREVIZOLI, M. R.; NEVES, M. F. Gestão da inovação em empresas da indústria sucroenergética. Revista de Administração da Fatea, Lorena, v. 10, n. 10, p. 6-21, 2015. Disponível em: <http://publicacoes.fatea.br/index.php/raf/article/viewArticle/1330 > . Acesso em: 10 abr. 2016.

UNIÃO DA INDÚSTRIA DE CANA-DE-AÇÚCAR. UNICA 2015. Mais de 100 usinas estão aptas a exportar para os Estados Unidos. [São Paulo, 2015a]. Disponível 
em: $\quad<$ http://www.unica.com.br/noticia/51056092036979688/mais-de-100-usinas-brasileiras-ja-estao-aptas-a-exportar-etanol-para-os-eua/> . Acesso em: 29 nov. 2015.

UNIÃO DA INDÚSTRIA DE CANA-DE-AÇÚCAR. UNICA. UNICA 2015b. Moagem de cana-de-açúcar e produção de açúcar e etanol - safra 2014-2015. Disponível em: $<$ http://www.unicadata.com.br/historico-de-producao-e-moagem.php?idMn $=31 \&$ tipoHistorico $=2 \&$ acao $=$ visualizar\&idTabela $=1802>$. Acesso em: 11 maio 2016 .

VOLPATO, G. L. O método lógico para redação científica. Reciis, v. 9, n. 1, p. 1-14, 2015. Disponível em: <http://www.reciis.icict.fiocruz.br/index.php/reciis/article/ view/932> . Acesso em: 27 abr. 2016.

Recebido em: 01/07/2017 Aceito em: 24/05/2018 